\title{
Clinical practice guidelines for the diagnosis and management of atopic dermatitis
}

\author{
Kanokvalai Kulthanan, ${ }^{1}$ Papapit Tuchinda, ${ }^{1}$ Rattanavalai Nitiyarom, ${ }^{2}$ Amornsri Chunharas, ${ }^{3}$ Hiroshi Chantaphakul, ${ }^{4}$ \\ Kobkul Aunhachoke, ${ }^{5}$ Leena Chularojanamontri, ${ }^{1}$ Natta Rajatanavin, ${ }^{6}$ Orathai Jirapongsananuruk, ${ }^{7}$ \\ Pakit Vichyanond, ${ }^{7}$ Pantipa Chatchatee, ${ }^{8}$ Pasuree Sangsupawanich, ${ }^{9}$ Siriwan Wananukul, ${ }^{10}$ Srisupalak Singalavanija ${ }^{11}$ \\ Suphattra Trakanwittayarak, ${ }^{1}$ Ticha Rerkpattanapipat, ${ }^{12}$ Torpong Thongngarm, ${ }^{13}$ Wanee Wisuthsarewong, ${ }^{2}$ \\ Wanida Limpongsanurak, ${ }^{11}$ Wasu Kamchaisatian, ${ }^{14}$ Nopadon Noppakun ${ }^{15}$
}

\begin{abstract}
Atopic dermatitis (AD), a chronic, relapsing dermatitis, is characterized by dry and pruritus skin in patients with a personal or family history of atopy. It affects up to $20 \%$ of children and $1-3 \%$ of adults in most countries worldwide, and leads to significant treatment costs and morbidity. These guidelines are developed in accordance with evidence-based publications and expert opinions. Following simple algorithms, the guidelines aim to assist adult and pediatric physicians in the better care of patients with AD. As with other diseases, there have been several diagnosis criteria proposed over time. Nonetheless, the classical Hanifin and Rajka criterion with no pathognomonic laboratory biomarkers is still the most widely used worldwide for the diagnosis of $\mathrm{AD}$. The management of $\mathrm{AD}$ must be considered case by case to provide suitable care for each patient. Basic therapy is focused on avoiding specific/unspecific provoking factors and hydrating skin. Topical anti-inflammatory treatments such as glucocorticoids and calcineurin inhibitors are suggested for disease flare, and proactive therapy is best for long-term control. Other therapies, including antimicrobial agents, systemic antihistamines, systemic anti-inflammatory agents, immunotherapy, phototherapy, and psychotherapy, are reviewed in these guidelines. Crisaborole, a new topical phosphodiesterase 4 inhibitor, can be used twice daily in AD patients over three months old. Dupilumab, a biological drug for patients with moderate-to-severe AD, may be considered in patients with no improvement from other systemic treatments.
\end{abstract}

Key words: atopic dermatitis, Thai, guidelines, diagnosis, management

\section{Affiliations:}

Department of Dermatology, Faculty of Medicine Siriraj Hospital, Mahidol University, Bangkok, Thailand

${ }^{2}$ Division of Pediatric Dermatology, Department of Pediatrics, Faculty of Medicine Siriraj Hospital, Mahidol University, Bangkok, Thailand

Division of Pediatric Dermatology, Department of Pediatrics, Faculty of Medicine Ramathibodi Hospital, Mahidol University, Bangkok, Thailand

${ }^{4}$ Division of Allergy and Clinical Immunology, Department of Medicine, Faculty of Medicine, Chulalongkorn University, Bangkok, Thailand

Division of Dermatology, Department of Medicine, Faculty of Medicine, Phramongkutklao Hospital, Bangkok, Thailand

${ }^{6}$ Division of Dermatology, Department of Medicine,

Faculty of Medicine Ramathibodi Hospital, Mahidol University, Bangkok, Thailand

Division of Allergy and Immunology, Department of Pediatrics, Faculty of Medicine Siriraj Hospital, Mahidol University, Bangkok, Thailand

\footnotetext{
${ }^{8}$ Pediatric Allergy \& Clinical Immunology Research Unit, Division of Allergy and Immunology, Department of Pediatrics, Faculty of Medicine, Chulalongkorn University, King Chulalongkorn Memorial Hospital, the Thai Red Cross Society, Bangkok, Thailand

${ }^{9}$ Division of Allergy and Immunology, Department of Pediatrics, Faculty of Medicine, Prince of Songkla University, Songkla, Thailand

${ }^{10}$ Division of Pediatric Dermatology, Department of Pediatrics, Faculty of Medicine Chulalongkorn University, Bangkok, Thailand

${ }^{11}$ Dermatology unit, Queen Sirikit National Institute of Child Health, Department of Medical Services, Ministry of Public Health, Bangkok, Thailand

${ }^{12}$ Division of Allergy and Immunology, Department of Medicine, Faculty of Medicine Ramathibodi Hospital, Mahidol University, Bangkok, Thailand

${ }^{13}$ Division of Allergy and Clinical Immunology, Department of Medicine, Faculty of Medicine Siriraj Hospital, Mahidol University, Bangkok, Thailand

${ }^{14}$ Division of Allergy and Clinical Immunology, Pediatrics Department, Samitivej Children's Hospital, Bangkok, Thailand

${ }^{15}$ Division of Dermatology, Department of Medicine, Faculty of Medicine, Chulalongkorn University, Bangkok, Thailand
} 
Corresponding author:

1. Papapit Tuchinda

Department of Dermatology, Faculty of Medicine Siriraj Hospital,

Mahidol University

2 Wanglang Road, Bangkoknoi, Bangkok 10700, Thailand

E-mail: papapitt@gmail.com

2. Rattanavalai Nitiyarom

Division of Pediatric Dermatology, Department of Pediatrics,

Faculty of Medicine Siriraj Hospital, Mahidol University

2 Wanglang Road, Bangkoknoi, Bangkok 10700, Thailand

E-mail: rattanavalai@gmail.com

$\begin{array}{ll}\text { Abbreviations } \\ \text { AD } & \text { atopic dermatitis } \\ \text { AH } & \text { antihistamines } \\ \text { ASIT } & \text { allergen-specific immunotherapy } \\ \text { CDLQI } & \text { Childrens Dermatology Life Quality Index } \\ \text { DLQI } & \text { Dermatology Life Quality Index } \\ \text { EASI } & \text { Eczema Area and Severity Index } \\ \text { FDA } & \text { Food and Drug Administration } \\ \text { IgE } & \text { immunoglobulin E } \\ \text { RCT } & \text { randomized controlled trial } \\ \text { SCORAD } & \text { Scoring of Atopic Dermatitis } \\ \text { SPT } & \text { skin prick test } \\ \text { S. aureus } & \text { Staphylococcus aureus } \\ \text { TCI } & \text { topical calcineurin inhibitors } \\ \text { TCS } & \text { topical corticosteroids } \\ \text { UV } & \text { ultraviolet }\end{array}$

\section{Introduction}

These clinical practice guidelines were a joint project among the Dermatological Society of Thailand; the Allergy, Asthma, and Immunology Association of Thailand; and the Pediatric Dermatological Society of Thailand. This collaboration aimed to develop guidelines that would provide effective practical advice to general practitioners and physicians in different specialties for caring patients with atopic dermatitis.

\section{Definition}

Atopic dermatitis (AD), also called atopic eczema, is a chronic, relapsing-remitting skin disease commonly found in childhood. Intense itching is the predominant symptom, while excessive scratching can cause excoriation and lichenification of the skin. ${ }^{1}$ The personal and family history regarding allergies such as allergic rhinitis, and/or asthma is related to $\mathrm{AD}$.

Despite several proposed criteria, the classic Hanifin and Rajka criterion with no pathognomonic laboratory biomarkers is still the most commonly used set for the diagnosis of $\mathrm{AD}^{2,3} \mathrm{AD}$ can be classified as intrinsic" (non-immunoglobulin E-associated) and "extrinsic" (immunoglobulin E-associated) AD. The latter is associated with an elevated level of total or allergen-specific immunoglobulin (Ig) $\mathrm{E}$ in serum or an IgE-mediated sensitization from skin prick test (SPT). Some patients with extrinsic $\mathrm{AD}$ also have a personal or family history of allergies such as allergic rhinitis, and/or asthma. ${ }^{4}$

\section{Epidemiology}

According to reports by the International Study of Asthma and Allergies in Childhood, phases I and III, allergic diseases are very common in Thailand. ${ }^{5}$ The prevalence of eczema symptoms in children aged 6-7 and 13-14 in this country has been $16.7 \%$ and $9.6 \%$, respectively. ${ }^{5} \mathrm{~A}$ cross-sectional, multi centers survey was carried out in Bangkok in 2017 and 2018 by the Global Asthma Network. This study showed that the cumulative and 12-month-period prevalence rates of eczema among all children in Bangkok were $15.8 \%$ and $14.2 \%$, respectively. ${ }^{6}$

Regarding the prevalence of eczema in adult patients, studies in 1975 and 1997 reported a prevalence of $15.2 \%$ and $9.4 \%$, respectively, among university students in Bangkok. ${ }^{7,8}$ In 2003, a study conducted at Naresuan University in the north of Thailand revealed an eczema prevalence of $15 \%$ among the students at that school. ${ }^{9}$ In East Asia, adult-onset AD was reported to be $21.4 \%$ among eczema patients. ${ }^{10}$ To date, there has been no study reporting the prevalence of adult-onset $\mathrm{AD}$ in Thailand.

\section{Clinical features of atopic dermatitis}

The clinical phenotype of $\mathrm{AD}$ is distinct and it changes with age during the course of the disease. The eczematous lesions can be manifested in acute (oozing, crusted, eroded vesicles, or papules on erythematous plaques), subacute (scaly erythematous papules or plaques), and chronic (lichenified, slightly pigmented, or excoriated plaques) features, with pruritus as a hallmark. There are three clinically distinct stages of AD - infancy, childhood, and adolescence/adulthood.

\section{Diagnostic approaches to atopic dermatitis}

The diagnosis of $\mathrm{AD}$ is based on one's history and clinical manifestations, such as morphology and the distribution of skin lesions. In 1980, major and minor criteria for a diagnosis of AD were proposed by Hanifin and Rajka (Table 1). ${ }^{11}$ Three of four major criteria and three of 23 minor criteria are required for a diagnosis of $\mathrm{AD}$. However, a large number of criteria are widely used in clinical practice.

Table 1. Features to be considered in the diagnosis of patients with atopic dermatitis by Hanifin \& Rajka (1980)

Major features (3 of 4 required)

1. Pruritus

2. Typical morphology and distribution

2.1 Flexural lichenification or linearity in adults

2.2 Facial and extensor involvement in infants and children

3. Chronic or chronically-relapsing dermatitis

4. Personal or family history of atopy, such as asthma, allergic rhinitis, atopic dermatitis

Minor features (3 of 23 required)

1. Xerosis

2. Ichthyosis/palmar hyperlinearity/keratosis pilaris

3. Immediate (type 1) skin test reactivity

4. Elevated serum immunoglobulin $\mathrm{E}$

5. Early age of onset

6. Tendency toward cutaneous infections (S. aureus and Herpes simplex virus)/impaired, cell-mediated immunity 
Table 1. (Continued)

Minor features (3 of 23 required) (Continued)

7. Tendency toward non-specific hand or foot dermatitis

8. Nipple eczema

9. Chelitis

10. Recurrent conjunctivitis

11. Dennie-Morgan infraorbital fold

12. Keratoconus

13. Anterior subcapsular cataract

14. Orbital darkening

15. Facial pallor/facial erythema

16. Pityriasis alba

17. Anterior neck fold

18. Itch when sweating

19. Intolerance to wool and lipid solvents

20. Perifollicular accentuation

21. Food intolerance

22. Course influence by environmental/emotional factors

23. White dermographism/delayed blanch

Patients, with a history of relapsing atopic dermatitis from an ingested food, skin prick test result, and/or specific immunoglobulin E

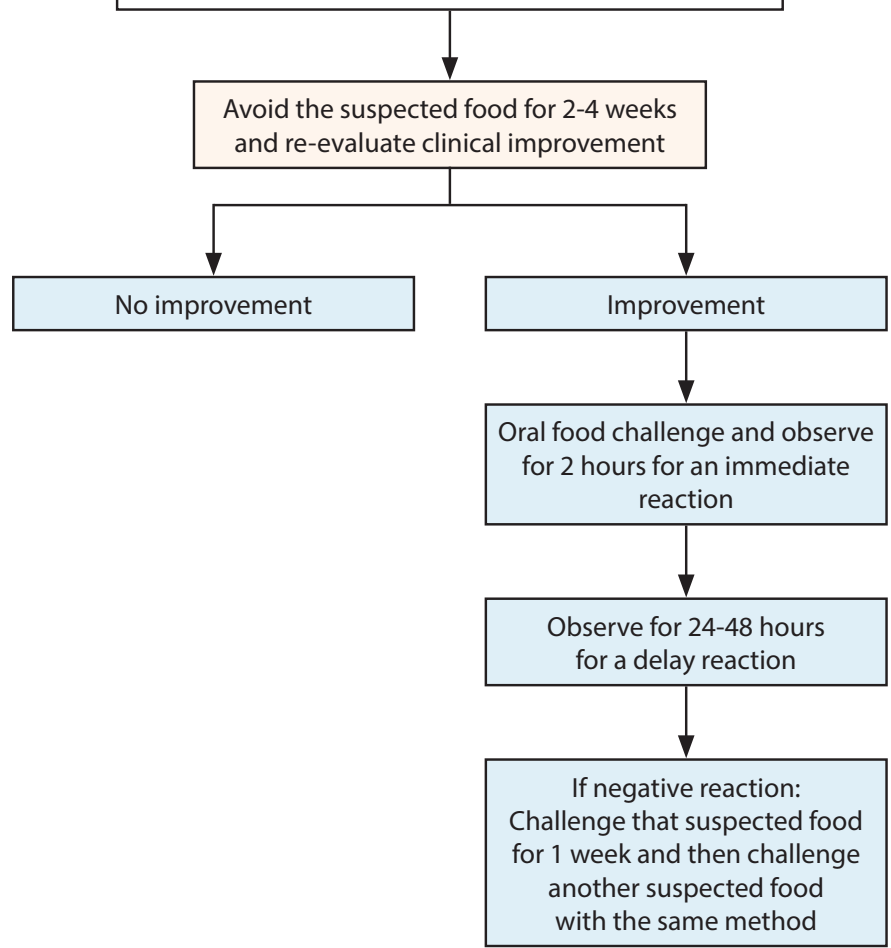

Figure 1. Diagnostic algorithm of oral food challenge test in patients with atopic dermatitis
$\mathrm{AD}$ is diagnosed according to its clinical presentation, rather than from the results of diagnostic testing. However, the use of percutaneous skin or in vitro tests, ranging from SPT to specific IgE to relevant allergens, can be used to identify potentially allergic triggering factors. ${ }^{2,12}$ Similarly, patch testing may be used as a screening tool in patients with $\mathrm{AD}$ who have recalcitrant disease or those with suspected allergic contact dermatitis. ${ }^{13}$

Clinicians have to be aware that food allergies relating to $\mathrm{AD}$ is commonly found in children under five years of age. The Food Allergy Expert Panel suggests that a food allergy test may be considered in children with moderate-to-severe $\mathrm{AD}$ who do not respond well after proper treatment. ${ }^{12}$ It should be noted that one-third of children with $\mathrm{AD}$ who test positive for food allergies do not have clinical symptoms after sensitization. Thus, an oral food challenge test (elimination and re-challenge) should be performed on children to confirm the diagnosis of food-induced eczema in patients with $\mathrm{AD}$ in order to avoid unnecessary food avoidance. Figure 1 demonstrates diagnostic algorithm for food allergy with oral food challenge test in patients with persistent moderate to severe $\mathrm{AD} \cdot{ }^{14}$

\section{Guidelines for the management of patients with} AD (Figure 2, 3, and Table 2) ) $^{3,15-21}$

The aims of $\mathrm{AD}$ treatment are to reduce symptoms (pruritus and dermatitis), prevent exacerbations, and optimize treatment to prevent therapeutic risks.

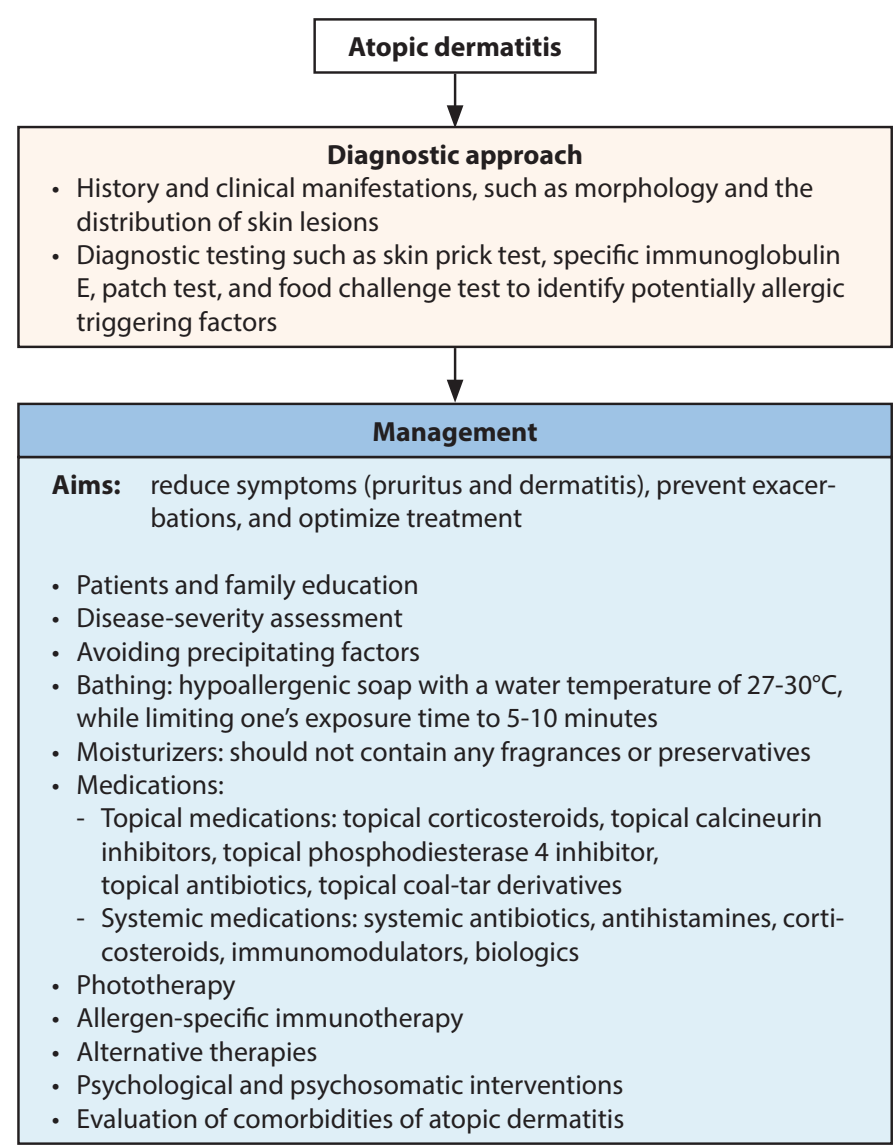

Figure 2. Diagnostic approach and management of atopic dermatitis 
Initial assessment of disease history, extent and severity including psychological distress and impact on family

\begin{tabular}{|l|}
\hline \multicolumn{1}{|c|}{ Skin care: } \\
- Apply emollients at least twice daily $(2 \mathrm{a}, \mathrm{A})$ \\
- Take a shower once or twice daily \\
- Do not take a hot shower \\
- Topical emollients apply immediately after taking a shower \\
Avoidance of trigger factors: \\
- Avoid allergens causing disease recurrence \\
- Avoid irritating substances such as soap, fur coat, hot or cold \\
temperature \\
\hline
\end{tabular}

\begin{tabular}{|l|}
\hline \multicolumn{1}{|c}{ Acute control of inflammation } \\
\hline Mild disease severity \\
- Mild-to-moderate potency topical corticosteroids applied twice \\
daily for 3-7 days until clinical improvement $(1 \mathrm{~b}, \mathrm{~A})$ and gradually \\
decrease the application \\
- Consider using topical calcineurin inhibitors $(1 \mathrm{a}, \mathrm{A})$ or crisaborole \\
$(1 \mathrm{a}, \mathrm{A})$
\end{tabular}

\section{Moderate-to-severe disease severity}

- Moderate-to-high potency topical corticosteroids should be applied twice daily for 3-7 days until clinical improvement $(1 \mathrm{~b}, \mathrm{~A})$ and gradually decrease the application

- Consider using topical calcineurin inhibitors $(1 \mathrm{a}, \mathrm{A})$ or crisaborole $(1 a, A)$

If the disease did not improve within $\mathbf{7}$ days, consider compliance, infection, misdiagnosis, contact dermatitis to medication or referring to specialists

\begin{tabular}{|l|}
\hline \multicolumn{1}{|c|}{ Long-term maintenance } \\
\hline Mild disease severity: \\
- Topical corticosteroids (1b, A), topical calcineurin inhibitors \\
(1a, A), crisaborole $2 \%$ (1a, A): as needed \\
\hline Moderate disease severity: \\
- Proactive therapy with topical anti-inflammatory drugs: apply \\
topical medications on old lesion or tend to develop the lesion \\
- Topical corticosteroids (1b, A): \\
- mild potency applied 2-3 times/week on face and sensitive \\
- moas \\
- moderate potency applied 2-3 times/week (excepting face and \\
- Topical calcineurin inhibitors (1a, A): applied 2-3 times/weeks \\
or not more than 2 times/day \\
- Crisaborole $2 \%$ (1a, A): applied twice daily \\
\hline Severe disease severity: Referring to specialists \\
- Phototherapy (1a, A) \\
- Systemic immunomodulators: ciclosporin (1a, A), \\
azathioprine (1b, A), methotrexate (4, C), \\
mycophenolate mofetil (4, C), corticosteroids (4, D) \\
- Consider treatment in some patients: wet wrap therapy \\
(1b, A) \\
- Dupilumab injection (1a, A) (dupilumab guidelines \\
for moderate-to-severe atopic dermatitis) \\
\hline
\end{tabular}

Figure 3. Algorithm for the treatment of atopic dermatitis
Table 2. Level of evidence and strength of recommendation of treatments.

$\begin{array}{lcc}\text { Treatment } & \begin{array}{c}\text { Level of } \\ \text { evidence }\end{array} & \begin{array}{c}\text { Strength of } \\ \text { recommendation }\end{array}\end{array}$

Moisturizer

A regular use of emollients should be helpful for treatment.

Topical corticosteroids

- Topical corticosteroids, with an improved risk/benefit ratio, are recommended in $\mathrm{AD}$.

Diluted topical corticosteroids may be used under wet wrap for a short-term period in acute $\mathrm{AD}$ to increase their efficacy.

Proactive therapy, e.g. twice-weekly application in the long-term follow-up, may help to reduce relapses.

Topical calcineurin inhibitors

- Topical calcineurin inhibitors have a significant effect, compared to vehicles in short-term and long-term treatment of $\mathrm{AD}$.

Topical calcineurin inhibitors are especially suitable for sensitive skin areas (the face, intertriginous areas, and anogenital area).

- Proactive therapy with twice-weekly application of topical calcineurin inhibitors may reduce relapses.

- Topical calcineurin inhibitors (tacrolimus and pimecrolimus) have been shown to be safe and effective for children under two years of age.

Topical phosphodiesterase 4 inhibitor

- Topical phosphodiesterase 4 inhibitor has been shown to be effective for children over three months of age.

Antimicrobial therapy

- A short-term treatment with systemic antibiotics may be beneficial if the skin is obviously superinfected with bacteria.

\section{Antihistamines}

There is not enough evidence to support the general use of both first- and second-generation $\mathrm{H}_{1}-\mathrm{AH}$ for pruritus in AD.

- The first generation of the sedative AH may allow for a better sleep in acute situations with exacerbations of eczema. 
Table 2. (Continued)

\begin{tabular}{|c|c|c|}
\hline Treatment & $\begin{array}{l}\text { Level of } \\
\text { evidence }\end{array}$ & $\begin{array}{l}\text { Strength of } \\
\text { recommendation }\end{array}$ \\
\hline \multicolumn{3}{|l|}{ Systemic corticosteroids } \\
\hline $\begin{array}{l}\text { Short-term (up to two weeks) } \\
\text { treatment with systemic corticoste- } \\
\text { roids may be an option in treating } \\
\text { an acute flare in exceptional cases } \\
\text { of AD. The daily dose should be } \\
\text { adjusted to and should not exceed } \\
0.5-1 \mathrm{mg} / \mathrm{kg} / \text { day }\end{array}$ & 4 & $\mathrm{D}$ \\
\hline \multicolumn{3}{|l|}{ Systemic immunomodulators } \\
\hline - Azathioprine & $1 b$ & A \\
\hline \multicolumn{3}{|l|}{ - Ciclosporin } \\
\hline $\begin{array}{l}\text { - Ciclosporin may be used in } \\
\text { chronic, severe cases of } \mathrm{AD} \text { in } \\
\text { adults. }\end{array}$ & la & A \\
\hline $\begin{array}{l}\text { - Ciclosporin may be used in } \\
\text { children and adolescent patients } \\
\text { showing a refractory or severe } \\
\text { course of disease. }\end{array}$ & $2 \mathrm{~b}$ & $\mathrm{~B}$ \\
\hline - Methotrexate & 4 & $\mathrm{C}$ \\
\hline - Mycophenolate mofetil & 4 & $\mathrm{C}$ \\
\hline \multicolumn{3}{|l|}{ Biologic agents } \\
\hline - Dupilumab & 1a & A \\
\hline - Omalizumab, rituximab, alefacept & 4 & $\mathrm{C}$ \\
\hline \multicolumn{3}{|l|}{ Phototherapy } \\
\hline $\begin{array}{l}\text { - Narrowband ultraviolet B is a more } \\
\text { effective treatment than broadband } \\
\text { ultraviolet B. }\end{array}$ & 1a & A \\
\hline $\begin{array}{l}\text { - Ultraviolet A1 is effective in the } \\
\text { acute phase. }\end{array}$ & la & A \\
\hline Allergen-specific immunotherapy & 1a & A \\
\hline $\begin{array}{l}\text { Psychological and psychosomatic } \\
\text { interventions }\end{array}$ & 1a & A \\
\hline
\end{tabular}

\section{Patients and family education}

Patients and their family should be educated in order to understand the course of the disease and to know how to properly manage themselves to control their symptoms and prevent an exacerbation of the disease. Interdisciplinary educational programs by dermatologists, allergists, pediatricians, psychologists, and nursing staff help to significantly improve their patients' quality of life.

\section{Disease-severity assessment}

The Eczema Area and Severity Index (EASI); the Rajka and Lengeland: Grading of severity of atopic dermatitis; and the Scoring of Atopic Dermatitis (SCORAD) are the most common scales for assessing disease severity in $\mathrm{AD}$ patients. These scales identify condition as mild, moderate, or severe. As regards the psychological impact, the Thai Dermatology
Life Quality Index (DLQI) ${ }^{22}$ and the Thai Children's Dermatology Life Quality Index (CDLQI) ${ }^{23}$ can be used. A disease-severity assessment is crucial in terms of treatment planning and further investigations.

\section{Avoiding precipitating factors}

Many factors can contribute to the exacerbation of $\mathrm{AD}$, such as infections, temperature, humidity, irritants, emotional stress, food allergens, and aeroallergens. Physicians should identify those aggravating factors and then advise patients to avoid them. Wisuthsarewong et al. ${ }^{24}$ reported the most common aggravating factors in 560 patients with $\mathrm{AD}$ aged less than 15 years were dry skin, seasonal change (especially summer and winter), dust, foods, furry pets, emotional change, furry toys, cigarette smoke, and skin infection, respectively.

In vitro testing for IgE antibodies or SPT can be used to identify potential allergens. However, as mentioned previously, specific IgE and SPT can produce a false positive result. In patients who are suspected of having a food allergy, relying on the results of specific IgE or SPT to food allergens may cause an unnecessary food avoidance. Food avoidance without a prior test can lead to malnutrition in children and a poorer quality of life and lower immunity. Thus, food allergy should be confirmed by doing an oral food challenge test before giving the patient any advice. ${ }^{12}$ Anaphylaxis has been reported in some patients with $\mathrm{AD}$ who stopped eating a particular food and then returned to it. The mechanism was believed to be a loss of desensitization.

\section{Management of AD}

\subsection{General recommendations for patients with $A D$}

Patients should avoid aggravating factors and substances such as rough cloth textures, heavy sun exposure, hot temperatures, steam and hot vapors, body scrubbing, and scratching. Patients are encouraged to wear loose clothing and to keep their nails short and clean.

\subsection{Bathing}

To avoid epidermal dehydration from bathing, it's best to use a hypoallergenic soap and a water temperature of 27 $30^{\circ} \mathrm{C}$, while limiting one's exposure time to 5-10 minutes. After gently drying the skin, topical emollients should be applied immediately to slightly humid skin. ${ }^{3}$ Bathing with antiseptic soaps or solutions should be avoided, as they can cause skin irritation.

Some soaps have added food ingredients such as hydrolyzed wheat protein, rice starch, and rice bran, which aim to improve the skin-barrier function. ${ }^{25}$ These soaps should be used with caution in patients with $\mathrm{AD}$, as several reports suggest that exposure to highly environmental food allergens increase the risk of epicutaneous food sensitization, particularly in patients with a skin-barrier dysfunction. ${ }^{26}$

Some studies have reported the benefits of body washes containing diluted sodium hypochlorite $(0.006 \%)$. They indicate that bathing the skin lesions with sodium hypochlorite $0.006 \%$ for $5-10$ minutes two to three times a week and then washing them with water can reduce the disease severity and the need for topical corticosteroids (TCS) or antibiotics, 
especially in patients with a recurrent skin infection. ${ }^{27,28}$ However, a systematic review and meta-analysis showed no significant differences compared to using a water bath alone. Therefore, such body washes should be performed under a physician's recommendation and care. ${ }^{29}$

\subsection{Moisturizers (2a, A)}

Using a skin moisturizer is a first step and can be an effective treatment. It can keep the skin hydrated for 2-6 hours, depending on the type of moisturizer. The amount that should be used on newborns, infants, young children, and adults ranges from 100, 150-200, to 250 g/week, respectively. ${ }^{30}$ Moisturizers for patients with $\mathrm{AD}$ should not contain any fragrance or preservatives. It is recommended to use plain moisturizers such as cold cream, cream base, $3-10 \%$ urea, or petrolatum twice daily. Regularly using a moisturizer can decrease the use of TCS and thus prevent an exacerbation of the disease.

The frequent use of prescribed and over-the-counter preparations containing peanut ${ }^{31}$ and oatmeal ${ }^{32}$ have been reported to potentially cause sensitization in children and to lead to food allergies. ${ }^{21}$

Whether an emollient should be applied before or after a topical drug depends on factors such as skin status, the vehicle types of moisturizers, the patient's convenience, and the physician's opinion. Generally, moisturizers (in a preparation of cream or lotion) should be applied first, followed by topical drugs on the inflamed skin. On the other hand, if a moisturizer is an ointment, the ointment should be applied after a topical drug on the inflamed skin. A certain period of time should lapse before applying one after another. ${ }^{2}$

\subsection{Topical corticosteroids (TCS) $(1 b, A)$}

Corticosteroids are the mainstay and effective treatment for patients with $\mathrm{AD}$. A mild-to-moderate potency of TCS should be applied twice daily on the inflamed skin during acute exacerbation, and then discontinued during disease remission. A proactive therapy is a long-term, intermittent application of anti-inflammatory agents to the previously affected skin, along with an ongoing emollient treatment of the unaffected skin. Studies have shown that the use of fluticasone propionate cream, ${ }^{33}$ methylprednisolone aceponate cream, ${ }^{33}$ and mometasone fuorate $\mathrm{cream}^{34}$ twice weekly on the previously affected skin significantly decreased the risk of AD relapses, compared to using a placebo in a proactive strategy. Another technique that can increase the efficacy of TCS is an occlusion. Wet-wrap therapy has been reported to be safe and effective in children with severe or refractory AD. ${ }^{35,36}$

TCS can be associated with significant adverse effects when used chronically. The local side effects of TCS are mainly skin changes such as skin atrophy, telangiectasias, purpura, hypopigmentation, acne, rosacea, striae distensae, and hypertrichosis. Systemic side effects may occur from extensive-area use or from the long-term use of TCS. These include glaucoma, cataract, adrenal insufficiency, Cushing's syndrome, and growth retardation. ${ }^{3}$

\subsection{Topical calcineurin inhibitors (TCI) (1a, A)}

TCI, as a second-line therapy in treating $\mathrm{AD}$, can be used over TCS in sensitive skin areas such as the face and intertriginous and anogenital sites, especially for topical longterm use. ${ }^{3}$ It is an effective treatment for the prevention, maintenance, and reduction of $\mathrm{AD}$ exacerbation. Typically, a twice-daily application is recommended during AD flares, followed by once daily during improvement, and then it should be discontinued during remission. However, a proactive strategy, such as applying TCI twice weekly on the previously inflamed skin, can also reduce disease exacerbation and improve the quality of life in such patients. ${ }^{37}$

\section{a. Tacrolimus}

Tacrolimus can be used for any severity of AD. Tacrolimus $0.03 \%$ ointment is recommended in children aged 2-16, while tacrolimus $0.1 \%$ ointment is recommended in patients aged over 16 years. Tacrolimus $0.1 \%$ showed no difference in potency when compared with moderate-to-potent TCS, ${ }^{38}$ but it was more potent than tacrolimus $0.03 \%$ and pimecrolimus $1 \%$. Tacrolimus $0.03 \%$ was superior to mild corticosteroids and pimecrolimus $1 \%{ }^{38}$ The efficacy and safety of tacrolimus ointment have also been reported in children under aged two years, ${ }^{38}$ as have the intermittent or continuous long-term use as a monotherapy for up to four years. ${ }^{38}$

\section{b. Pimecrolimus}

Pimecrolimus $1 \%$ is effective for mild-to-moderate AD on the face and other sensitive skin areas. ${ }^{39}$ Pimecrolimus $1 \%$ had similar efficacy to low-to-medium potent TCS. ${ }^{39}$ In Thailand, it is recommended to use on infants over three months old. The safety of the long-term use of pimecrolimus as a monotherapy up to five years has been reported.

\subsection{Topical phosphodiesterase 4 inhibitor (1a, A)}

Crisaborole $2 \%$ ointment has been approved by the EU and US FDA for patients with mild-to-moderate AD. It acts by inhibiting phosphodiesterase 4 and reducing inflammatory cytokines, resulting in a significant decrease in inflammatory skin and pruritic symptoms. It can be used twice daily in mild-to-moderate AD patients aged over three months. Pain, burning, and stinging sensations have been reported regarding application sites in some patients. ${ }^{40,41}$ Currently, it is not available in Thailand. It is expected to be available in 2021.

\subsection{Antimicrobial therapy $(2 b, B)$}

Antimicrobial therapy can be used in AD patients with a superimposed bacterial infection. Suitable topical or systemic antibiotics should act against Staphylococcus aureus (S. aureus) and Streptococcus pyogenes. The optimal duration of treatment is 1-2 weeks. Adding topical antibiotics to topical steroids can decrease the amount of $S$. aureus from the skin. ${ }^{42}$ The prolonged use of antibiotics is not recommended. The 2010 Cochrane review of randomized controlled trials (RCTs) reported a lack of quality trials to support the use of antimicrobial and antiseptic preparations for $\mathrm{AD}$ treatment. Antibiotics are not recommended for the treatment of $\mathrm{AD}$ that does not have superimposed bacterial infection. ${ }^{43}$ 


\subsection{Topical coal-tar derivatives}

Currently, there is no adequate data to support the clinical efficacy of coal tar in patients with AD. ${ }^{17}$ However, it can control an exacerbation of $\mathrm{AD}$ in some patients.

\subsection{Systemic antihistamines}

Although there is no adequate data to prove the efficacy of systemic antihistamines (AHs) in patients with $\mathrm{AD}$, such drugs are widely used in acute flares against pruritus. Sedating AHs may be helpful for the reduction of itches and sleepiness during disease flares. ${ }^{21}$ It should be noted that topical AHs are not recommended because there are no adequate evidences of topical AHs to control AD symptoms. Moreover, topical AHs can cause allergic or photoallergic contact dermatitis. ${ }^{17}$

\subsection{Systemic corticosteroids $(4, D)$}

For patients with an uncontrolled disease with TCS, oral prednisolone or intramuscular injections of triamcinolone can be administered as a short-term treatment. Oral prednisolone at a dose of $0.5-1 \mathrm{mg} / \mathrm{kg} /$ day for up to maximum 2 weeks can be given. Long-term use, especially in children, is not recommended, due to side effects such as growth restriction and hormonal suppression. ${ }^{21}$

\subsection{Systemic immunomodulators}

\section{a. Ciclosporin $(1 a, A)$}

Ciclosporin is suggested as a first-line, short-term treatment for moderate-to-severe $\mathrm{AD}^{44} \mathrm{~A}$ higher dosage of $5 \mathrm{mg} / \mathrm{kg} /$ day yields a better response and is more efficacious than a lower dosage. ${ }^{45}$ Nonetheless, the lowest dose that can control the disease is recommended to minimize its side effects. Major concerned side effects are hypertension and renal impairment. Thus, treatment should be started with a dosage of $3 \mathrm{mg} / \mathrm{kg} / \mathrm{day}$, and then slightly decreased at a dose of $0.5-1 \mathrm{mg} / \mathrm{kg} /$ day every two weeks. ${ }^{15}$ In addition, a combination of ciclosporin with ultraviolet (UV) therapy is not recommended. UV protection is strongly suggested during ciclosporin use. ${ }^{15}$

\section{b. Azathioprine (1b, A)}

Azathioprine is recommended as a second-line treatment for moderate-to-severe $\mathrm{AD}$ patients who are unresponsive or who develop adverse effects from ciclosporin. ${ }^{45}$ The suggested initial dose is $50 \mathrm{mg} /$ day in adult, and this dosage should be titrated according to the clinical response and its possible side effects. The recommended dosages of azathioprine in adults and children are 1-3 mg/ $\mathrm{kg} /$ day and $1-2 \mathrm{mg} / \mathrm{kg} /$ day, respectively. It should not be used in combination with UV therapy. ${ }^{15}$

\section{c. Methotrexate $(4, C)$}

Methotrexate is recommended as a third-line treatment for adults with severe AD. The starting doses are 5-15 mg/ week in adults and $10-15 \mathrm{mg} / \mathrm{m}^{2} /$ week in children. The dosage should be increased weekly in steps of $2.5-5 \mathrm{mg} /$ week, not exceeding $25 \mathrm{mg} /$ week..$^{15}$ As methotrexate is teratogenic, men and women of childbearing potential must use effective contraception during therapy. ${ }^{45}$

\section{d. Mycophenolate mofetil $(4, C)$}

There are some reports on the efficacy of mycophenolate mofetil in patients with refractory $\mathrm{AD}$ who are unresponsive or develop adverse effects to ciclosporin. The recommended dosages in children are $600-1200 \mathrm{mg} / \mathrm{m}^{2} /$ day, divided twice daily, and not exceeding $2 \mathrm{~g} /$ day in adult. ${ }^{15}$

\subsection{Biologics}

\section{a. Dupilumab (1a, A)}

Dupilumab is a fully human monoclonal antibody that blocks the common $a$-chain of interleukin- 4 and interleukin-13 receptors. It has been approved as a first-line treatment by the EU and US FDA in 2017 for patients aged over six years with moderate-to-severe $\mathrm{AD}$ whose disease is not adequately controlled with topical prescription therapies or when systemic therapies are not advisable. ${ }^{15}$

For the treatment of Thai patients aged 12 years and older with moderate-to-severe $\mathrm{AD}$ whose disease is not adequately controlled with topical prescription therapies or when those therapies are not advisable. It can be used with or without TCS. The algorithm of dupilumab treatment is illustrated in Figure 4.

Patients with atopic dermatitis aged 12 years and older

1. Under the care of a dermatologist and/or an allergist

2. Diagnosed with atopic dermatitis for a period of at least 1 year

3. Moderate-to-severe atopic dermatitis

Eczema Area and Severity Index (EASI) score $\geq 20$ after treated with topical corticosteroids plus moisturizers

4. The disease cannot be controlled with medium-to-high potency topical corticosteroids and irresponsive systemic therapies at least 2 of $6(4.1-4.6)$ with the reduction in the EASI score less than $50 \%$

or Can not discontinue systemic therapies

or Have contraindications or side effects of systemic therapies

4.1 Receiving systemic corticosteroids $0.5 \mathrm{mg} / \mathrm{kg} /$ day for at least 2 weeks

4.2 Receiving ciclosporin 3-5 mg/kg/day for at least 8 weeks

4.3 Receiving azathioprine $1-3 \mathrm{mg} / \mathrm{kg} /$ day (adult) or $1-2 \mathrm{mg} / \mathrm{kg} /$ day (children) for at least 12 weeks

4.4 Receiving narrowband ultraviolet $B$ or psoralen and ultraviolet A 2-3 times/week or ultraviolet A1 3-5 times/ week at least 24 times or for 12 weeks

4.5 Receiving methotrexate $\geq 15 \mathrm{mg} /$ week (adult) and $15 \mathrm{mg} / \mathrm{m}^{2} /$ week (children) for at least 12 weeks

4.6 Receiving mycophenolate mofetil $2 \mathrm{~g} /$ day (adult) and $600-1200 \mathrm{mg} / \mathrm{m}^{2} /$ day not exceed $2 \mathrm{~g} /$ day (children)

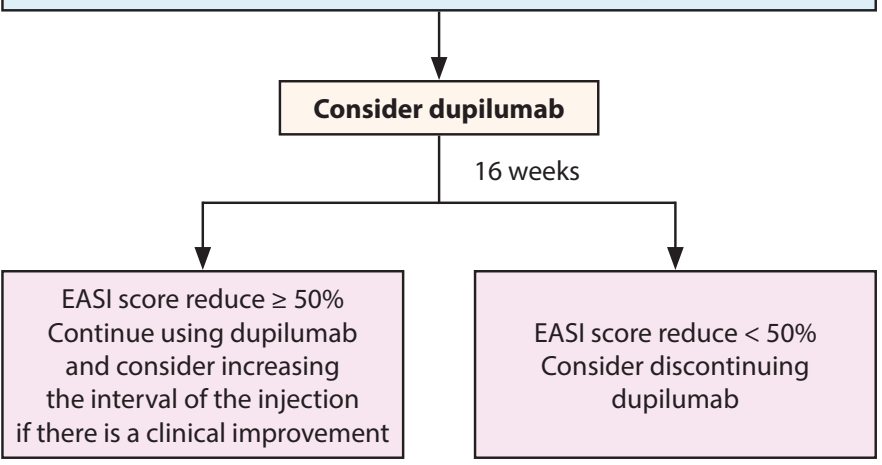

Figure 4. Dupilumab guidelines for moderate-to-severe atopic dermatitis 


\section{b. Omalizumab, rituximab or ustekinumab $(4, C)$}

No adequate evidence is available to support the injection of omalizumab, rituximab, or ustekinumab. ${ }^{15}$ They are not approved by the US FDA for patients with moderate-to-severe $\mathrm{AD}$. These agents may be considered in patients who are unresponsive to other therapies.

\subsection{Phototherapy $(1 b, A)$}

Phototherapy is an option for adult patients and children aged 12 and older. ${ }^{16}$

\subsection{Allergen-specific immunotherapy (ASIT) $(1 a, A)$}

ASIT is a potentially effective treatment modality for IgE-mediated AD. A subcutaneous administration using house-dust mites is most commonly employed for ASIT in AD. ${ }^{46-48}$ A study by Chu et al. ${ }^{49}$ reported that patients with $\mathrm{AD}$ can benefit from ASIT with cat and/or dog dander, as confirmed in allergic asthma and allergic rhinitis. It can be administered sublingually or subcutaneously. Some studies have shown that ASIT can reduce the disease's severity and improve the quality of life of patients with AD. ${ }^{50}$ ASIT therapy should be conducted under specialists' care.

\subsection{Alternative therapies}

Vitamin supplements may play an effective role in the treatment of AD. Vitamin D supplementation, especially in $\mathrm{AD}$ patients with a low level of serum vitamin $\mathrm{D}$, can reduce AD symptoms. Nevertheless, the best therapeutic dose of vitamin $\mathrm{D}$ supplement in $\mathrm{AD}$ remains unknown. ${ }^{51}$ Benefits from other supplements, such as hempseed probiotics, selenium, pyridoxine, fish oil, docosahexaenoic acid, zinc, and evening primrose oil, are uncertain. ${ }^{52}$ Thus, vitamin supplementation is not routinely recommended for use in $\mathrm{AD}$ patients. ${ }^{15}$

\subsection{Quality of life and emotional stress (1a, A)}

$\mathrm{AD}$ has a significant effect on the quality of life of patients and their families. Stress and emotional factors can exacerbate the disease. ${ }^{12}$ Psychosomatic counseling, psychotherapeutic approaches, behavioral-therapy techniques, autogenetic training, and relaxation techniques are beneficial in the management of patients with $\mathrm{AD} .^{15}$

\section{Prevention}

\subsection{Primary prevention}

There is evidence that exclusive breastfeeding for three to four months reduces the risk of developing $\mathrm{AD}$ in children up to two years old. ${ }^{53}$ Apart from breastfeeding, feeding high-risk infants (with a positive family history of atopy) with a hydrolyzed cow's milk formula either in extensive or partial forms, rather than cow's milk formula, may reduce the risk of AD. ${ }^{54-}$ ${ }^{57}$ For high-risk infants whose mother has insufficient breast milk, the use of partially hydrolyzed whey formulas and extensively hydrolyzed casein formulas, rather than cow's milk, may reduce the risk of developing $\mathrm{AD}$ in children from infancy to aged six years. ${ }^{57}$ There is no evidence that dietary avoidance during pregnancy and breast-feeding in high-risk mothers can reduce the risk to children of developing AD. Moreover, diet restrictions in pregnant women can lead to maternal or fetal nutritional deficiencies, or both. ${ }^{58}$
Probiotic supplementation to prevent the risk of developing $\mathrm{AD}$ in children has been intensively studied. A systematic review and meta-analysis of 28 studies (27 RCTs and one non-RCT) has demonstrated that probiotic supplementation during the prenatal and/or postnatal (early-life) period can reduce the risk of developing $\mathrm{AD}$ in infants and older children. ${ }^{59}$ Other studies have indicated that probiotic supplementation can decrease the risk of $\mathrm{AD}$, but it did not reduce the risk of developing wheezing and/or asthma. ${ }^{60}$ Although probiotic supplementation has been intensively studied, how to supplement it (the types and quantities of microorganisms, the dose, and the duration) still needs to be investigated. Thus, to date, there is still no agreed-upon recommendation regarding supplementing probiotics to reduce the risk of $\mathrm{AD}$ in children.

There has been recent evidence that applying moisturizers as soon as possible after birth (within a maximum of three weeks) and continuing this until aged six months can reduce the risk of developing $\mathrm{AD}$ at aged six months. ${ }^{61}$ Applying moisturizers on a regular basis during the first six months of life seems to be a cost-effective strategy to prevent $\mathrm{AD} .^{62}$ One RCT demonstrated that applying ceramide-dominant emollient on a regular basis (two times/day) from the first week of life up to 26 and 32 weeks resulting in a significant reduction in food sensitization in children aged one year old. ${ }^{63}$

On the other hand, Cochrane Database showed that applying moisturizers during the first year of life in healthy infant and infant with high-risk $\mathrm{AD}$ was not effective in preventing eczema by one to two years of age, and probably increase risk of skin infection. However, there was a heterogeneity of those studies that affected the certainty of evidence. ${ }^{64}$

\subsection{Secondary preventions}

Secondary preventions are meant to avoid possible allergens and precipitating factors.

\section{Specialists' referral}

Consulting with AD specialists, such as allergists and dermatologists, is suggested for those with a doubtful diagnosis of $\mathrm{AD}$, those with refractory to first-line therapy, a severity of $\mathrm{AD}$ with significant dysfunction, a suspicious immune deficiency, and/or food allergies or an allergy to other allergens.

\section{Comorbidities of $A D$}

$\mathrm{AD}$ is associated with atopic and non-atopic comorbidities. Atopic diseases, particularly allergic rhinitis, asthma, food allergy, and atopy-associated eye disorders, are not only the common comorbidities but one of the diagnostic criteria for AD. Non-atopic comorbidities involve cutaneous infection, sleep disturbance, anxiety, and depression. Mechanisms of interaction between $\mathrm{AD}$ and its comorbidities could be multidirectional. Therefore, worsening of which could have a negative impact on others. Thorough assessment and proper management of those comorbidities are crucial for improving overall treatment outcomes. ${ }^{65}$ 
Patients with $\mathrm{AD}$ have an increased risk of developing allergic rhinitis and asthma. A study of Thai children demonstrated that $40 \%$ of those with $\mathrm{AD}$ developed other allergic diseases. Ten percent of them developed asthma and 36\% developed allergic rhinitis. ${ }^{24}$

Patients with AD had an increased prevalence of acute urticaria. One study reported that $16.2 \%$ of patients with $\mathrm{AD}$ had such hives. ${ }^{66}$ Early-onset $\mathrm{AD}$ was also reported to be a risk factor in developing chronic spontaneous urticaria. ${ }^{67}$ On the other hand, $50.2 \%$ of patients with acute urticaria were reported to have $\mathrm{AD}$, asthma, or allergic rhinitis. ${ }^{68}$

\section{Prognosis}

$\mathrm{AD}$ is the first step in the atopic march, followed by allergic rhinitis and asthma. These problems will increase among patients who have a family history of atopy. Generally, the onset of $\mathrm{AD}$ is found during infancy. Fifty percent and $85 \%$ of patients will develop the disease during their first or their fifth year of life, respectively. A study focused on Thai children with $\mathrm{AD}$ showed that $73 \%$ of them developed the disease in their first two years, with a mild degree of severity $(30.9 \%$,) a moderate degree (51.8\%), and a severe degree (17.3\%). Factors that influenced the severity of the disease included an early age of onset, a history of cow's milk allergy, and a history of food allergy. ${ }^{24}$

Patients with age onset of $\mathrm{AD}$ during the first two years of life tend to have a higher rate of disease remission than those who develop the disease during adolescence or adulthood. Patients with a high degree of disease severity tend to have the disease persistently until adulthood ${ }^{69}$ A systematic review and meta-analysis have revealed that $80 \%$ of patients had disease remission at the age of eight, and fewer than $5 \%$ of patients continued to have the disease for 20 years after being diagnosed. ${ }^{69}$

A study of Thai children with AD showed that those with mild, moderate, and severe $\mathrm{AD}$ would experience disease remission at the median age of 3.4, 3.5, and 7.0 years, respectively. Two-thirds of patients with AD would have disease remission within their first five years. ${ }^{70}$

\section{Conclusion}

$\mathrm{AD}$ is a common chronic skin disease that can severely affect physical and psychological aspects of the patients. $\mathrm{Pa}$ tients and family education, disease assessment, identifying aggravating factors, treating comorbidities, and medicines optimization are all important to provide the suitable care for patients with AD. New systemic targeted therapies such as dupilumab are effective, safe, and licensed treatment option with potential ocular side effects. Other biologicals targeting key pathways in the atopic immune response and Janus kinase inhibitors are among emerging treatment options. Further studies with a long-term follow up are recommended to investigate the impact on $\mathrm{AD}$-associated comorbidities, in addition to skin manifestations, and more targeted, or even personalized, treatment approaches for AD.

\section{Conflict of interest disclosure}

The authors declare that they have no conflicts of interest in this manuscript.

\section{References}

1. Leung DY. Atopic dermatitis: new insights and opportunities for therapeutic intervention. J Allergy Clin Immunol. 2000;105:860-76.

2. Ring J, Alomar A, Bieber T, Deleuran M, Fink-Wagner A, Gelmetti C, et al. Guidelines for treatment of atopic eczema (atopic dermatitis) part I. J Eur Acad Dermatol Venereol. 2012;26:1045-60.

3. Wollenberg A, Barbarot S, Bieber T, Christen-Zaech S, Deleuran M, Fink-Wagner A, et al. Consensus-based European guidelines for treatment of atopic eczema (atopic dermatitis) in adults and children: part I. J Eur Acad Dermatol Venereol. 2018;32:657-82.

4. Wuthrich B, Schmid-Grendelmeier P. The atopic eczema/dermatitis syndrome. Epidemiology, natural course, and immunology of the IgE -associated ("extrinsic") and the nonallergic ("intrinsic") AEDS. J Investig Allergol Clin Immunol. 2003;13:1-5.

5. Asher MI, Montefort S, Bjorksten B, Lai CK, Strachan DP, Weiland SK, et al. Worldwide time trends in the prevalence of symptoms of asthma, allergic rhinoconjunctivitis, and eczema in childhood: ISAAC Phases One and Three repeat multicountry cross-sectional surveys. Lancet. 2006; 368:733-43.

6. Chinratanapisit S, Suratannon N, Pacharn P, Sritipsukho P, Vichyanond P. Prevalence and severity of asthma, rhinoconjunctivitis and eczema in children from the Bangkok area: The Global Asthma Network (GAN) Phase I. Asian Pac J Allergy Immunol. 2019;37:226-31.

7. Tuchinda M. Prevalence of allergic diseases. Siriraj Hos Gaz. 1978;30: 1285-96.

8. Vichyanond P, Sunthornchart S, Singhirannusorn V, Ruangrat S, Kaewsomboon S, Visitsunthorn N. Prevalence of asthma, allergic rhinitis and eczema among university students in Bangkok. Respir Med. 2002;96: 34-8.

9. Uthaisangsook S. Prevalence of asthma, rhinitis, and eczema in the university population of Phitsanulok, Thailand. Asian Pac J Allergy Immunol. 2007;25:127-32.

10. Lee HH, Patel KR, Singam V, Rastogi S, Silverberg JI. A systematic review and meta-analysis of the prevalence and phenotype of adult-onset atopic dermatitis. J Am Acad Dermatol. 2019;80:1526-32 e7.

11. Hanifin JM, Rajka G. Diagnostic features of atopic dermatitis. Acta Derm Venereol. 1980;92:44-7.

12. Schneider L, Tilles S, Lio P, Boguniewicz M, Beck L, LeBovidge J, et al. Atopic dermatitis: a practice parameter update 2012. J Allergy Clin Immunol. 2013;131:295-9 e1-27.

13. Chen JK, Jacob SE, Nedorost ST, Hanifin JM, Simpson EL, Boguniewicz $\mathrm{M}$, et al. A pragmatic approach to patch testing atopic dermatitis patients: Clinical recommendations based on expert consensus opinion. Dermatitis. 2016;27:186-92.

14. Werfel T, Ballmer-Weber B, Eigenmann PA, Niggemann B, Rance F, Turjanmaa K, et al. Eczematous reactions to food in atopic eczema: position paper of the EAACI and GA2LEN. Allergy. 2007;62:723-8.

15. Wollenberg A, Barbarot S, Bieber T, Christen-Zaech S, Deleuran M, Fink-Wagner A, et al. Consensus-based European guidelines for treatment of atopic eczema (atopic dermatitis) in adults and children: part II. J Eur Acad Dermatol Venereol. 2018;32:850-78.

16. Boguniewicz M, Fonacier L, Guttman-Yassky E, Ong PY, Silverberg J, Farrar JR. Atopic dermatitis yardstick: Practical recommendations for an evolving therapeutic landscape. Ann Allergy Asthma Immunol. 2018; 120:10-22 e2.

17. Eichenfield LF, Tom WL, Berger TG, Krol A, Paller AS, Schwarzenberger $\mathrm{K}$, et al. Guidelines of care for the management of atopic dermatitis: section 2. Management and treatment of atopic dermatitis with topical therapies. J Am Acad Dermatol. 2014;71:116-32.

18. Eichenfield LF, Tom WL, Chamlin SL, Feldman SR, Hanifin JM, Simpson EL, et al. Guidelines of care for the management of atopic dermatitis: section 1. Diagnosis and assessment of atopic dermatitis. J Am Acad Dermatol. 2014;70:338-51.

19. Sidbury R, Davis DM, Cohen DE, Cordoro KM, Berger TG, Bergman JN, et al. Guidelines of care for the management of atopic dermatitis: section 3. Management and treatment with phototherapy and systemic agents. J Am Acad Dermatol. 2014;71:327-49. 
20. Sidbury R, Tom WL, Bergman JN, Cooper KD, Silverman RA, Berger TG, et al. Guidelines of care for the management of atopic dermatitis: Section 4. Prevention of disease flares and use of adjunctive therapies and approaches. J Am Acad Dermatol. 2014;71:1218-33.

21. Wollenberg A, Christen-Zach S, Taieb A, Paul C, Thyssen JP, de Bruin-Weller M, et al. ETFAD/EADV Eczema task force 2020 position paper on diagnosis and treatment of atopic dermatitis in adults and children. J Eur Acad Dermatol Venereol. 2020;34:2717-44.

22. Kulthanan K, Jiamton S, Wanitphakdeedecha R, Chantharujikaphong S. The Validity and Reliability of the Dermatology Life Quality Index (DLQI) in Thais. Thai J Dermatol. 2004;20:113-23.

23. Wisuthsarewong W, Nitiyarom R, Ngamcherdtrakul P. The Validity and Reliability of the Thai Version of Children's Dermatology Life Quality Index (CDLQI). J Med Assoc Thai. 2015;98:968-73.

24. Wisuthsarewong W, Limpongsanurak W, Chunharas A, Jetsrisuparb C, Wananukul S, Chatproedprai S, et al. Atopic dermatitis at pediatric tertiary care centers in Thailand: A multicenter study. Southeast Asian J Trop Med Public Health. 2017;88:88-95.

25. Fukutomi Y, Taniguchi M, Nakamura H, Akiyama K. Epidemiological link between wheat allergy and exposure to hydrolyzed wheat protein in facial soap. Allergy. 2014;69:1405-11.

26. Tham EH, Rajakulendran M, Lee BW, Van Bever HPS. Epicutaneous sensitization to food allergens in atopic dermatitis: What do we know? Pediatr Allergy Immunol. 2020;31:7-18.

27. Majewski S, Bhattacharya T, Asztalos M, Bohaty B, Durham KC, West DP, et al. Sodium hypochlorite body wash in the management of Staphylococcus aureus-colonized moderate-to-severe atopic dermatitis in infants, children, and adolescents. Pediatr Dermatol. 2019;36:442-7.

28. Maarouf M, Hendricks AJ, Shi VY. Bathing additives for atopic dermatitis - A systematic review. Dermatitis. 2019;30:191-7.

29. Chopra R, Vakharia PP, Sacotte R, Silverberg JI. Efficacy of bleach baths in reducing severity of atopic dermatitis: A systematic review and meta -analysis. Ann Allergy Asthma Immunol. 2017;119:435-40.

30. Eichenfield LF, Boguniewicz M, Simpson EL, Russell JJ, Block JK, Feldman SR, et al. Translating atopic dermatitis management guidelines into practice for primary care providers. Pediatrics. 2015;136:554-65.

31. Lack G, Fox D, Northstone K, Golding J, Avon Longitudinal Study of P, Children Study T. Factors associated with the development of peanut allergy in childhood. N Engl J Med. 2003;348:977-85.

32. Boussault P, Leaute-Labreze C, Saubusse E, Maurice-Tison S, Perromat $\mathrm{M}$, Roul S, et al. Oat sensitization in children with atopic dermatitis: prevalence, risks and associated factors. Allergy. 2007;62:1251-6.

33. Schmitt J, von Kobyletzki L, Svensson A, Apfelbacher C. Efficacy and tolerability of proactive treatment with topical corticosteroids and calcineurin inhibitors for atopic eczema: systematic review and meta -analysis of randomized controlled trials. Br J Dermatol. 2011;164:415-28.

34. Faergemann J, Christensen O, Sjovall P, Johnsson A, Hersle K, Nordin P, et al. An open study of efficacy and safety of long-term treatment with mometasone furoate fatty cream in the treatment of adult patients with atopic dermatitis. J Eur Acad Dermatol Venereol. 2000;14:393-6.

35. Devillers AC, Oranje AP. Wet-wrap treatment in children with atopic dermatitis: a practical guideline. Pediatr Dermatol. 2012;29:24-7.

36. Nicol NH, Boguniewicz M. Wet Wrap Therapy in Moderate to Severe Atopic Dermatitis. Immunol Allergy Clin North Am. 2017;37:123-39.

37. Wollenberg A, Reitamo S, Girolomoni G, Lahfa M, Ruzicka T, Healy E, et al. Proactive treatment of atopic dermatitis in adults with $0.1 \%$ tacrolimus ointment. Allergy. 2008;63:742-50.

38. Cury Martins J, Martins C, Aoki V, Gois AF, Ishii HA, da Silva EM. Topical tacrolimus for atopic dermatitis. Cochrane Database Syst Rev. 2015:CD009864.

39. Sigurgeirsson B, Boznanski A, Todd G, Vertruyen A, Schuttelaar ML, Zhu $\mathrm{X}$, et al. Safety and efficacy of pimecrolimus in atopic dermatitis: a 5-year randomized trial. Pediatrics. 2015;135:597-606.

40. Paller AS, Tom WL, Lebwohl MG, Blumenthal RL, Boguniewicz M, Call RS, et al. Efficacy and safety of crisaborole ointment, a novel, nonsteroidal phosphodiesterase 4 (PDE4) inhibitor for the topical treatment of atopic dermatitis (AD) in children and adults. J Am Acad Dermatol. 2016;75: 494-503 e6

41. Schlessinger J, Shepard JS, Gower R, Su JC, Lynde C, Cha A, et al. Safety, effectiveness, and pharmacokinetics of crisaborole in infants aged 3 to $<24$ months with mild-to-moderate atopic eermatitis: A phase IV open-label study (CrisADe CARE 1). Am J Clin Dermatol. 2020;21:275-84.
42. Gong JQ, Lin L, Lin T, Hao F, Zeng FQ, Bi ZG, et al. Skin colonization by Staphylococcus aureus in patients with eczema and atopic dermatitis and relevant combined topical therapy: a double-blind multicentre randomized controlled trial. Br J Dermatol. 2006;155:680-7.

43. Bath-Hextall FJ, Birnie AJ, Ravenscroft JC, Williams HC. Interventions to reduce Staphylococcus aureus in the management of atopic eczema: an updated Cochrane review. Br J Dermatol. 2010;163:12-26.

44. Schmitt J, Schmitt N, Meurer M. Cyclosporin in the treatment of patients with atopic eczema - a systematic review and meta-analysis. J Eur Acad Dermatol Venereol. 2007;21:606-19.

45. Roekevisch E, Spuls PI, Kuester D, Limpens J, Schmitt J. Efficacy and safety of systemic treatments for moderate-to-severe atopic dermatitis: a systematic review. J Allergy Clin Immunol. 2014;133:429-38.

46. Werfel T, Breuer K, Rueff F, Przybilla B, Worm M, Grewe M, et al. Usefulness of specific immunotherapy in patients with atopic dermatitis and allergic sensitization to house dust mites: a multi-centre, randomized, dose-response study. Allergy. 2006;61:202-5.

47. Liu L, Chen J, Xu J, Yang Q, Gu C, Ni C, et al. Sublingual immunotherapy of atopic dermatitis in mite-sensitized patients: a multi-centre, randomized double-blind, placebo-controlled study. Artif Cells Nanomed Biotechnol. 2019;47:3540-7.

48. Novak N, Bieber T, Hoffmann M, Folster-Holst R, Homey B, Werfel T, et al Efficacy and safety of subcutaneous allergen-specific immunotherapy with depigmented polymerized mite extract in atopic dermatitis. J Allergy Clin Immunol. 2012;130:925-31 e4.

49. Chu H, Park KH, Kim SM, Lee JH, Park JW, Lee KH, et al. Allergen-specific immunotherapy for patients with atopic dermatitis sensitized to animal dander. Immun Inflamm Dis. 2020;8:165-9.

50. Tam HH, Calderon MA, Manikam L, Nankervis H, Nunez IG, Williams $\mathrm{HC}$, et al. Specific allergen immunotherapy for the treatment of atopic eczema: a Cochrane systematic review. Allergy. 2016;71:1345-56.

51. Kim G, Bae JH. Vitamin D and atopic dermatitis: A systematic review and meta-analysis. Nutrition. 2016;32:913-20

52. Gray NA, Dhana A, Stein DJ, Khumalo NP. Zinc and atopic dermatitis: a systematic review and meta-analysis. J Eur Acad Dermatol Venereol. 2019;33:1042-50

53. Greer FR, Sicherer SH, Burks AW, Committee On N, Section On A Immunology. The effects of early nutritional interventions on the development of atopic disease in infants and children: The role of maternal dietary restriction, breastfeeding, hydrolyzed formulas, and timing of introduction of allergenic complementary foods. Pediatrics. 2019;143.

54. Muraro A, Dreborg S, Halken S, Host A, Niggemann B, Aalberse R, et al. Dietary prevention of allergic diseases in infants and small children. Part II. Evaluation of methods in allergy prevention studies and sensitization markers. Definitions and diagnostic criteria of allergic diseases. Pediatr Allergy Immunol. 2004;15:196-205.

55. Szajewska $\mathrm{H}$, Horvath A. Meta-analysis of the evidence for a partially hydrolyzed $100 \%$ whey formula for the prevention of allergic diseases. Curr Med Res Opin. 2010;26:423-37.

56. von Berg A, Koletzko S, Grubl A, Filipiak-Pittroff B, Wichmann HE, Bauer $\mathrm{CP}$, et al. The effect of hydrolyzed cow's milk formula for allergy prevention in the first year of life: the German Infant Nutritional Intervention Study, a randomized double-blind trial. J Allergy Clin Immunol. 2003;111:533-40.

57. von Berg A, Filipiak-Pittroff B, Kramer U, Link E, Bollrath C, Brockow I, et al. Preventive effect of hydrolyzed infant formulas persists until age 6 years: long-term results from the German Infant Nutritional Intervention Study (GINI). J Allergy Clin Immunol. 2008;121:1442-7.

58. Kramer MS, Kakuma R. Maternal dietary antigen avoidance during pregnancy or lactation, or both, for preventing or treating atopic disease in the child. Cochrane Database Syst Rev. 2012:CD000133.

59. Li L, Han Z, Niu X, Zhang G, Jia Y, Zhang S, et al. Probiotic Supplementation for Prevention of Atopic Dermatitis in Infants and Children: A Systematic Review and Meta-analysis. Am J Clin Dermatol. 2019;20:367-77.

60. Elazab N, Mendy A, Gasana J, Vieira ER, Quizon A, Forno E. Probiotic administration in early life, atopy, and asthma: a meta-analysis of clinical trials. Pediatrics. 2013;132:e666-76.

61. Simpson EL, Chalmers JR, Hanifin JM, Thomas KS, Cork MJ, McLean WH, et al. Emollient enhancement of the skin barrier from birth offers effective atopic dermatitis prevention. J Allergy Clin Immunol. 2014;134:818-23.

62. Xu S, Immaneni S, Hazen GB, Silverberg JI, Paller AS, Lio PA. Cost -effectiveness of prophylactic moisturization for atopic dermatitis. JAMA Pediatr. 2017;171:e163909. 
63. Lowe A, Su J, Tang M, Lodge CJ, Matheson M, Allen KJ, et al. PEBBLES study protocol: a randomised controlled trial to prevent atopic dermatitis, food allergy and sensitisation in infants with a family history of allergic disease using a skin barrier improvement strategy. BMJ Open. 2019;9: e024594.

64. Kelleher MM, Cro S, Cornelius V, Lodrup Carlsen KC, Skjerven HO, Rehbinder EM, et al. Skin care interventions in infants for preventing eczema and food allergy. Cochrane Database Syst Rev. 2021;2:CD013534.

65. Silverberg JI. Comorbidities and the impact of atopic dermatitis. Ann Allergy Asthma Immunol. 2019;123:144-51.

66. Simons FE. Prevention of acute urticaria in young children with atopic dermatitis. J Allergy Clin Immunol. 2001;107:703-6.
67. Kitsioulis NA, Papadopoulos NG, Kostoudi S, Manousakis E, Douladiris $\mathrm{N}$, Xepapadaki P. Assessment of atopic dermatitis as a risk factor for chronic spontaneous urticaria in a pediatric population. Allergy Asthma Proc. 2018;39:445-8.

68. Zuberbier T. Acute urticaria. In: Greaves MW, Kaplan AP, editors. Urticaria and angioedema. New York: Marcel Dekker;. 2004:P141-7.

69. Kim JP, Chao LX, Simpson EL, Silverberg JI. Persistence of atopic dermatitis (AD): A systematic review and meta-analysis. J Am Acad Dermatol. 2016;75:681-7 e11.

70. Wananukul S, Chatproedprai S, Tempark T, Phuthongkamt W, Chatchatee P. The natural course of childhood atopic dermatitis: a retrospective cohort study. Asian Pac J Allergy Immunol. 2015;33:161-8. 